\title{
Parental bonding among polygamous families and its effects on adolescent psychological well-being
}

\author{
Mohammad AL-Sharfi \\ ALBaha University \\ Karen Pfeffer \\ School of Psychology \\ University of Lincoln \\ Corresponding author \\ Dr. Mohammad AL-Sharfi \\ Department of Psychology \\ Collage of Education
}

\begin{abstract}
The quality of parent-adolescent relationships is important for adolescent life outcomes and well-being. This study investigated parent-adolescent relationships, psychological well-being and problem behaviour among adolescents from polygamous families in Saudi Arabia. Adolescents (145 boys, 121 girls, 130 from polygamous families, 136 from monogamous families) completed measures of parental bonding, self-esteem, satisfaction with life, depression, bullying and victimization. Compared to adolescents from monogamous families, those from polygamous families reported lower father care, mother care, self-esteem, and satisfaction with life, also higher depression, and bullying and victimization scores. Perceptions of father care and mother care predicted self-esteem, satisfaction with life and depression. In addition, perceptions of mother care predicted victimization. Results will benefit school counsellors and professionals who work with polygamous families.
\end{abstract}

KEYWORDS: Parenting, Family, Adolescence, Well-Bing,

Polygamy .

\section{Introduction}

The quality of the parent-adolescent relationship is an important factor determining adolescent life outcomes and well-being (Berk, 2010; Bowlby, 1988; Parker, Tupling \& Brown, 1979, Rosen, 2016). Also, the parent-adolescent relationship is an important family 
process that is affected by family structure (Falci, 1997). One type of family structure that is common in several countries is polygamy. There are several forms of polygamy and the most common form is polygyny. Polygyny occurs when a man has more than one wife at the same time. Polygynous family structures can be found in various countries in the Middle East, Asia and Africa. In Middle Eastern societies, polygyny is influenced by cultural, social, economic, political and religious factors (Al-Krenawi, 2014; Al-Shamsi, \& Fulcher, 2005). Despite the prevalence of polygyny, there is insufficient research on the development of children and adolescents in polygamous families (Al-Sharfi, Pfeffer \& Miller, 2016).

Although some researchers emphasised potential benefits to children living in large polygynous families (Swanson, Massey \& Payne, 1972; Valsiner, 1989), more recent research has highlighted detrimental effects on children and adolescents, including internalizing problems, externalizing problems and mental health problems (Al-Krenawi, Graham \& Slonim-Nevo, 2002; Al-Krenwai and Slonim-Nevo, 2008; Al-Shamsi \& Fulcher, 2005; Al-Sharfi, 2015; Elbedour, Onwuegbuzie \& Alatamin, 2003). Studies of adolescents in polygynous families found that they had poorer mental health than those in monogamous families, lower self-esteem and less satisfaction with life (Al-Krenawi, Graham \& Slonim-Nevo, 2002; Al-Sharfi, 2015; Riaz, 1996). Also, more social problems were reported among adolescents from polygynous families than monogamous families, including more sibling conflicts, worse relationships with friends and higher bullying rates (Al-Krenawi \& Lightman, 2000; Al-Krenawi \& Slonim-Nevo, 2008; Al-Sharfi, 2015).

Reasons for such detrimental effects include the negative effects of polygyny on mothers, on fathers and on the relationships between mothers and fathers (Al-Krenawi, 2014; Al-Shamsi \& Fulcher, 2005; Elbedour, Onwuegbuzie, Caridine \& Abu-Saad, 2002; Shephard, 2012). For example, mothers in polygynous families were reported to experience depression, anxiety, hostility, psychoticism, psychiatric disorder, reduced life satisfaction and reduced marital satisfaction (Shepard, 2012). Studies found that the negative effects of polygyny on mothers affected their children (Elbedour et al, 2002) and weakened the parent-child bond (Cherian, 1994). Adolescents from

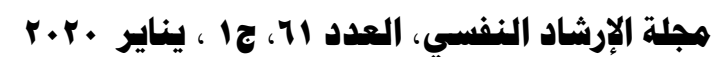


polygynous families reported higher levels of family dysfunction, lower family cohesion and worse relationships with their father than adolescents in monogamous families (Al-Krenawi et al, 2002; AlKrenawi \& Slonim-Nevo, 2008; Elbedour et al, 2007). Also, the effects of poor relationships between polygamous marriage partners were found to negatively affect adolescents (Al-Shamsi \& Fulcher, 2005). In summary, polygyny has been found to affect the relationship between the marriage partners as well as the relationship between parents and their children.

\section{The current study}

The focus of this research was to investigate adolescent wellbeing in Saudi Arabia, especially among polygynous families. Polygyny is practised in Saudi Arabia more than in other Middle Eastern societies (Alkhateep, 2007; Al Sharfi, 2009). In Saudi society, the prevalence of polygynous families has been influenced by the economic revolution through the last 30 years as well as other social, cultural and religious factors (Ymani, 2008; Al-Seef, 2008). There is a scarcity of research on polygynous families in Saudi Arabia, especially from a psychological perspective. Therefore, the first aim of this research was to investigate the effects of polygyny on adolescent well-being and behaviour in Saudi Arabia. Following previous research, this study investigated differences between adolescents from two different family structures, polygynous and monogamous families in parent-adolescent relationships, psychological well-being and bullying. Based on previous research, we hypothesized that adolescents from polygamous families would have lower indicators of psychological well-being than adolescents from monogamous families, more bullying and victimization behaviours.

Also, as previous research on polygynous families highlighted problems in family relationships, we were interested in the relationship between parents and their children. Researchers have emphasised the important role of parental bonding for healthy development, especially in adolescence (AL-Muhareeb, 2003; ALSharfi, 2009; Rigby, Slee \& Martin, 2007; Sun, 2001). Therefore, a second aim of this study was to investigate differences between adolescents from polygamous and monogamous families with regards

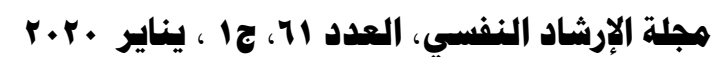


to their relationships with their parents. It was predicted that the relationship with the father will be different for children and adolescents from polygamous families when compared to those from monogamous families. Polygynous father's time and resources are expected to be divided between wives and the children of each wife which means that fathers are likely to spend less time with their children in polygamous families. There are very few studies on the parent-adolescent relationship among polygamous families and further research is needed in this area.

Also, a very few studies have compared the effects of polygamy on children and adolescents of different ages, we investigated age group differences. Adolescents may rely less on their parents or their well-being and models of behaviour as they grow and develop (Berk, 2010). However, from an Arabic culture perspective, parents continue to be important throughout adolescence and adulthood (Al-Sharfi, 2009). Therefore our research question was 'Are there differences between younger and older adolescents in parentadolescent relationships, psychological well-being and bullying?'

As the experience of polygyny is different for men and women, we were interested in determining the extent of gender differences in the experiences of polygyny during childhood. Among the few studies that found differences between boys and girls in polygynous families, Elbedour et al (2000) found gender differences in achievement in one academic subject and Al-Krenawi et al (2006) found gender differences in attitudes towards polygyny. Our research question was 'Are there differences between males and females in parent-adolescent relationships, psychological well-being and bullying?'. So we can write the hypotheses of the study as following:

- There are differences between adolescents from polygamous and monogamous families in father's care comparing age group and gender.

- There are differences between adolescents from polygamous and monogamous families in mother's care comparing age group and gender.

- There are differences between adolescents from polygamous and monogamous families in self-esteem comparing age group and gender.

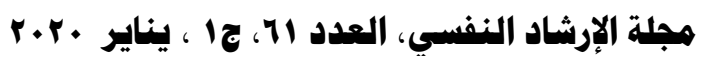



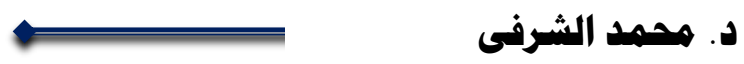

- There are differences between adolescents from polygamous and monogamous families in satisfaction with life comparing age group and gender.

- There are differences between adolescents from polygamous and monogamous families in depression comparing age group and gender.

- There are differences between adolescents from polygamous and monogamous families in bullying comparing age group and gender.

- There are differences between adolescents from polygamous and monogamous families in bullying of victimization comparing age group and gender.

Finally, we were interested in the whether family structure and the quality of the parent-adolescent relationship can predict psychological well-being and problem behaviours (bullying and victimization) among adolescents in Saudi Arabia.

\section{Method}

\section{Participants}

Participants were 266 students, 145 boys and 121 girls; 130 students were from polygamous families and 136 from monogamous families in Riyadh city. The mean age for the participants was 15.55 years old and the range ages from 13 to 18 years old. Participants were sampled by using two types of selection; participants from polygamous families were selected through teachers' identification. Adolescents from monogamous families were sampled randomly from school registers. Participants were divided into two age groups; early adolescence $(13-15$ years, $\mathrm{n}=131)$ and later adolescence $(16-18$ years old, $\mathrm{n}=135)$.

\section{Materials}

A demographic questionnaire asked questions about age, gender and family. Measures of self-esteem (Rosenberg, 1979), satisfaction with life (Diener et al, 1985), depression (Lovibond \& Lovibond, 1985), bullying and victimization (Abu- Khazal, 2009) were used. Also, subscales to measure adolescents' perceptions of parental care from the Parental Bonding Instrument (Parker et al., 1979) were used. All questionnaires have been validated for use with

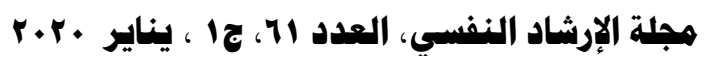


Parental bonding among polygamous families and its effects on adolescent psychological well-being

Arab adolescents and were considered to be culturally relevant instruments. All materials prepared in English were translated and back-translated into Arabic for use in Saudi Arabia. Also, consent forms, information sheets and debrief sheets for teachers, parents and participants were provided. Psychometric properties of the instruments were calculated for this sample using Cronbach alpha to show the internal consistency. For self-esteem alpha $=.72$, for satisfaction with life alpha $=.74$, for depression alpha $=.87$, for bullying alpha $=.96$, for victimization of bullying alpha $=.97$, for the Mother Care scale from the PBI alpha $=.85$, for the Father Care scale from the PBI alpha $=.91$,

\section{Scoring procedure}

Each item in the self-esteem scale was scored on a 4 point scale with higher scores showing higher self-esteem. Each item in the Satisfaction with Life scale was scored using a 7 point scale with higher scores showing more satisfaction with life. Items in the depression scale were scored on a 4 point scale with higher scores showing more depression. Items on the bullying and victimization scales were scored using 5 point scales with higher scores indicating more bullying and more victimization. Each item in the PBI was scored on a 4-point scale with higher scores indicating more parental care.

\section{Procedure}

After the researcher received the consent forms from the parents, principals, and students, the questionnaires and tests were administered in two sessions by the researcher to avoid tiring the participants. For the girls' school, school counsellors administered the questionnaires for cultural reasons.

\section{Ethics}

The ethics of this study were approved by the University of Lincoln School of Psychology Research and Ethics Committee and ALBaha University in Saudi Arabia. Also, permission was given from the Saudi Cultural Attaché and Education management. Parents gave written consent. Participants were informed that they do not have to participate if they do not want to, that they do not have to answer every question and that they can withdraw from the research at any time and withdraw their results up to two weeks later.
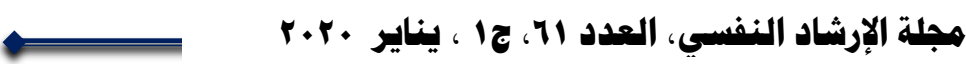


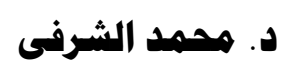

\section{Results}

The effects of family structure (2 levels: polygynous, monogamous), gender (2 levels: male, female) and age ( 2 levels: early and late adolescence) on, self-esteem, satisfaction with life, depression, bullying and victimization, as well as parental bonding were analysed using three-way ANOVAs.

\section{Self-esteem comparisons}

Self-esteem scores were significantly higher for adolescents from monogamous families than polygamous families (see Figure 1); $\mathrm{F}(1,258)=1.36 .660, \mathrm{p}<0.001$, partial eta squared $=.346$. There was no significant difference for boys and girls, $F(1,258)=0.48, p>$ 0.05 . There was no significant effect of age group, $\mathrm{F}(1,258)=0.54$, $\mathrm{p}>0.05$, and also no significant interactions.

Figure (1)

Mean Self-Esteem scores for adolescents from polygamous and monogamous families comparing age group and gender:

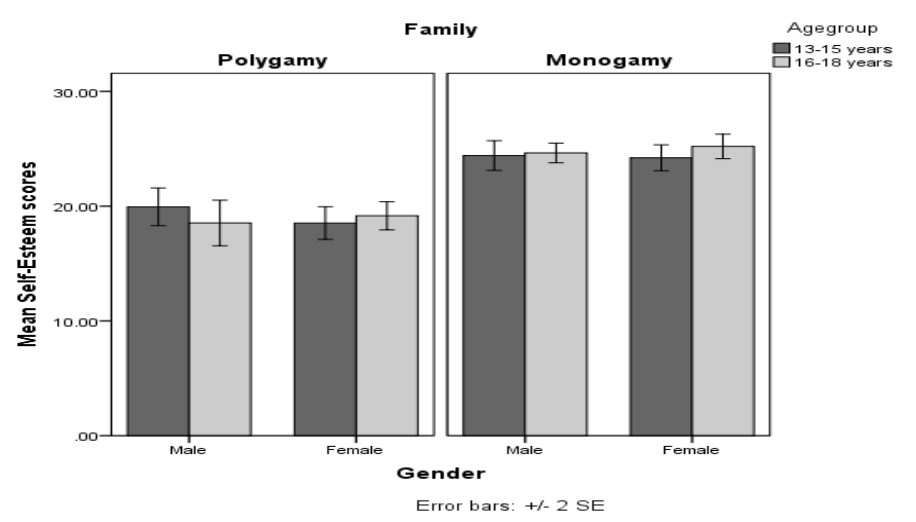




\section{Figure (2)}

Mean Satisfaction with Life scores for adolescents from polygamous and monogamous families comparing age group and gender :

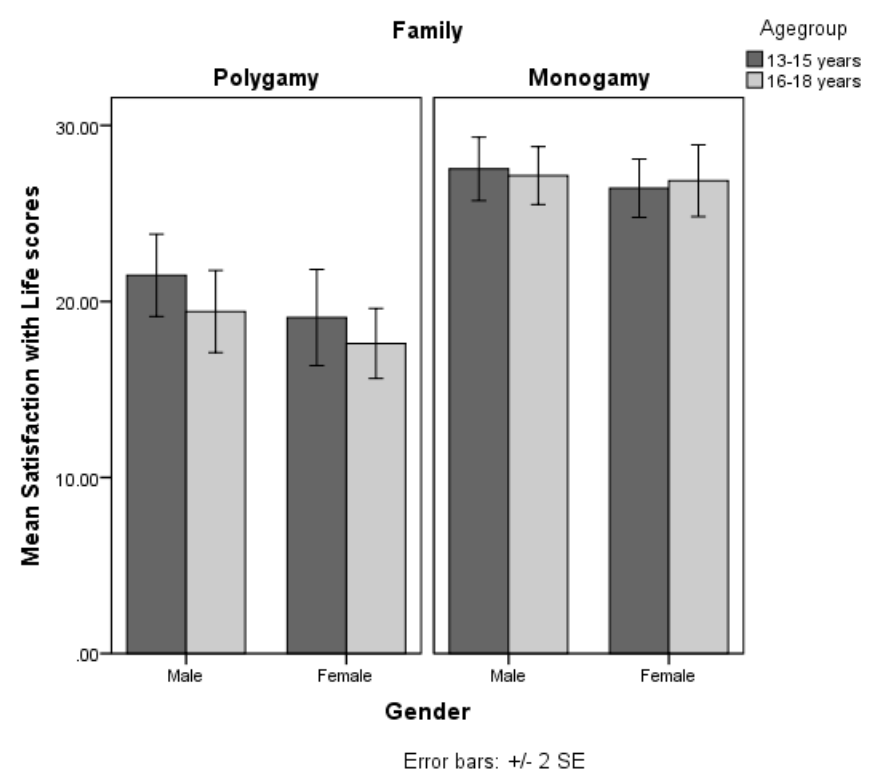

\section{Satisfaction with Life comparisons}

Figure 2 shows that satisfaction with life scores were higher for adolescents from monogamous families than those from polygamous families; $\mathrm{F}(1,258)=102.441, \mathrm{p}<0.001$, partial eta squared $=.284$. There was no significant difference for boys and girls, $\mathrm{F}(1,258)=3.488, \mathrm{p}>0.05$. There was no significant effect of age group, $\mathrm{F}(1,258)=1.346, \mathrm{p}>0.05$, and also no significant interactions.

\section{Depression scale comparisons}

Figure 3 shows that depression scores were higher for adolescents from polygamous families than those from monogamous families; $F(1,258)=179.336, p<0.001$, partial eta squared $=.410$. There was no significant difference for boys and girls, $\mathrm{F}(1,258)=$ $1.163, \mathrm{p}>0.05$. Older adolescents scored higher than younger adolescents, $\mathrm{F}(1,258)=3.898, \mathrm{p}=0.049$, partial eta squared $=.015$. There were no significant interactions. Although the age difference was significant, further analyses using independent-tests found no

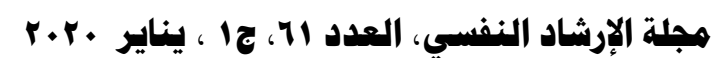




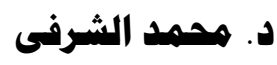

significant age differences for the overall sample t $(264)=0.70, \mathrm{p}>$ .05 ; for polygamous families $\mathrm{t}(126)=1.331, \mathrm{p}>0.05$; for monogamous families $\mathrm{t}(136)=1.738 \mathrm{p}>0.05$; for boys $\mathrm{t}(142)=$ $0.114, \mathrm{p}>0.05$; for girls $\mathrm{t}(120)=0.833, \mathrm{p}>0.05$.

Figure(3)

Mean Depression scores for adolescents from polygamous and monogamous families comparing age group and gender:

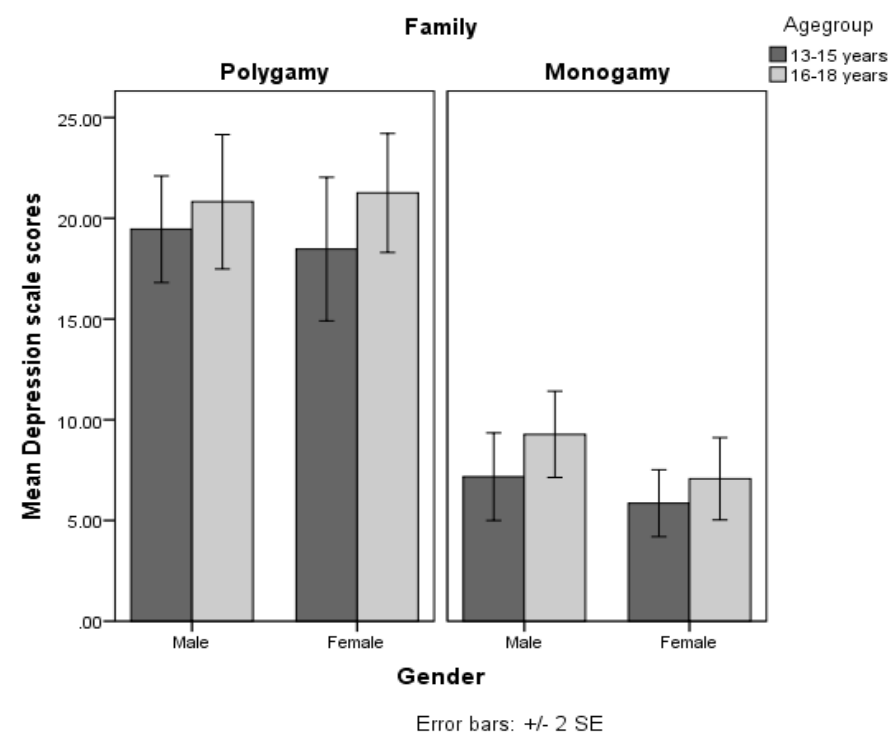

\section{Bullying scale comparisons}

Figure 4 shows that bullying scores were higher for adolescents from polygamous families than those from monogamous families; $\mathrm{F}(1,258)=114.884, \mathrm{p}=0.001$, partial eta squared $=.308$. There was no significant difference for boys and girls, $\mathrm{F}(1,258)=$ $2.680, p>0.05$ and no significant age differences, $F(1,258)=1.370$, p> 0.05. Although Figure 4 shows that girls from polygamous families scored higher than any other group, there were no statistically significant interactions.

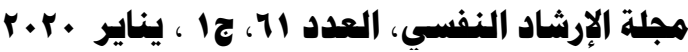


Parental bonding among polygamous families and its effects on adolescent psychological well-being

Figure (4)

Mean bullying scores for adolescents from polygamous and monogamous families comparing age group and gender

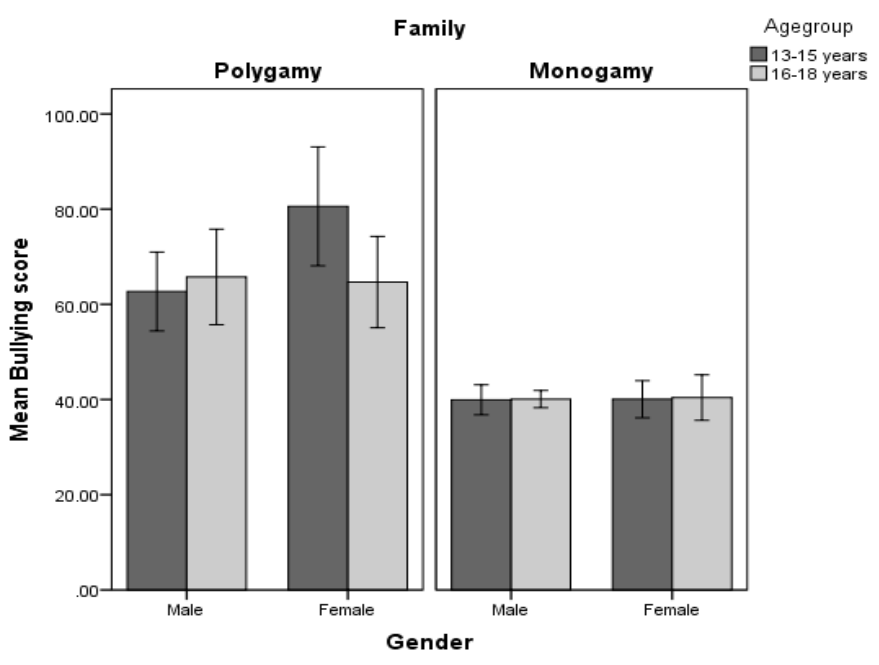

Error bars: +/- $2 \mathrm{SE}$

Figure (5)

Mean victimization scores for adolescents from polygamous and monogamous families comparing age group and gender:

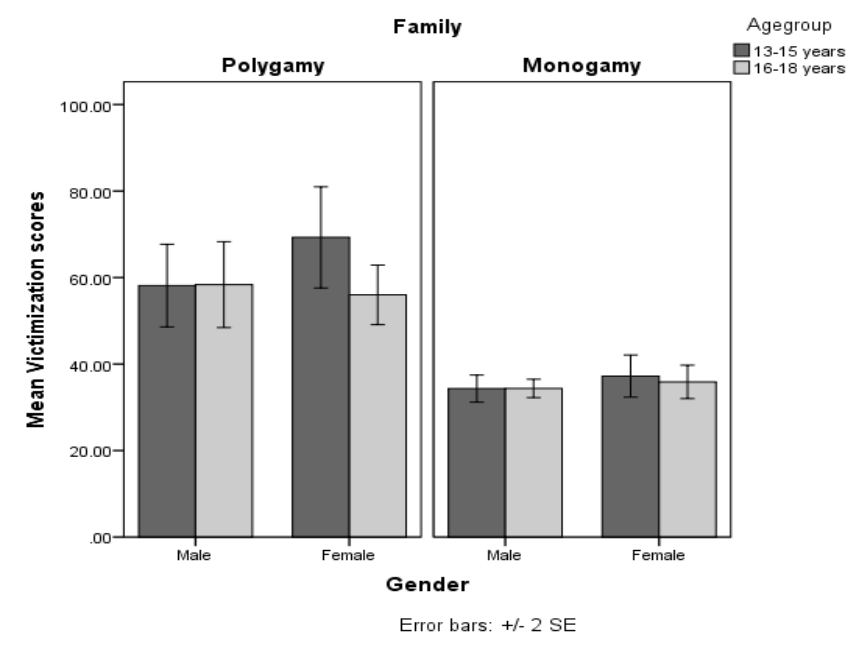

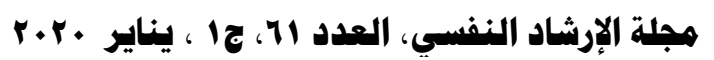

$(\varepsilon \vee \varepsilon)$ 

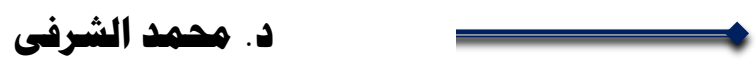

\section{Bullying victimization scale comparisons}

Figure 5 shows that victimization scores were higher for adolescents from polygamous families than those from monogamous families; $F(1,258)=96.891, p=0.001$, partial eta squared $=.273$. There was no significant difference for boys and girls, $\mathrm{F}(1,258)=$ $1.683, \mathrm{p}>0.05$ and no significant age group difference, $\mathrm{F}(1,258)=$ $2.006, \mathrm{p}>0.05$. Although Figure 5 shows that girls from polygamous families scored higher than any other group, there were no statistically significant interactions.

\section{Parental Care comparisons}

For Father Care, significantly lower scores were found for participants from polygamous than monogamous families; $F(1,258)$ $=155.247, \mathrm{p}<0.001$, partial eta squared $=.381$. No significant difference was found between boys and girls $\mathrm{F}(1,258)=2.367, \mathrm{p}>$ 0.05 . No significant difference was found between older and younger adolescents; $F(1,258)=2.220, p>0.05$. There were no significant interactions between any of the variables.

For Mother Care, significantly lower scores were found for participants from polygamous families than from monogamous families; $\mathrm{F}(1,262)=90.699, \mathrm{p}<0.001$, partial eta squared $=.26$. There was no statistically significant effect of gender; $F(1,262)=$ $.296, \mathrm{p}>0.05$. Also, no significant effect was found for age group, $\mathrm{F}$ $(1,262)=1.529, \mathrm{p}>0.05$ (see Figure 7$)$. There were significant interactions for family, gender, and stage; $F(1,262)=4.002, p<0.05$, partial eta squared $=.015$. Post hoc t-tests with Bonferroni corrections found younger males from monogamous families had higher scores than older males from monogamous families; $\mathrm{t}=2.435$, $\mathrm{df}=79, \mathrm{p}=$ 0.017 . However, this was found to be nonsignificant after applying Bonferroni corrections ( $\mathrm{p}=0.05 / 14=0.004)$. 
Parental bonding among polygamous families and its effects on adolescent psychological well-being

Figure (6)

Mean scores on the Father Care subscale of the PBI for adolescents from polygamous and monogamous families comparing age group and gender:

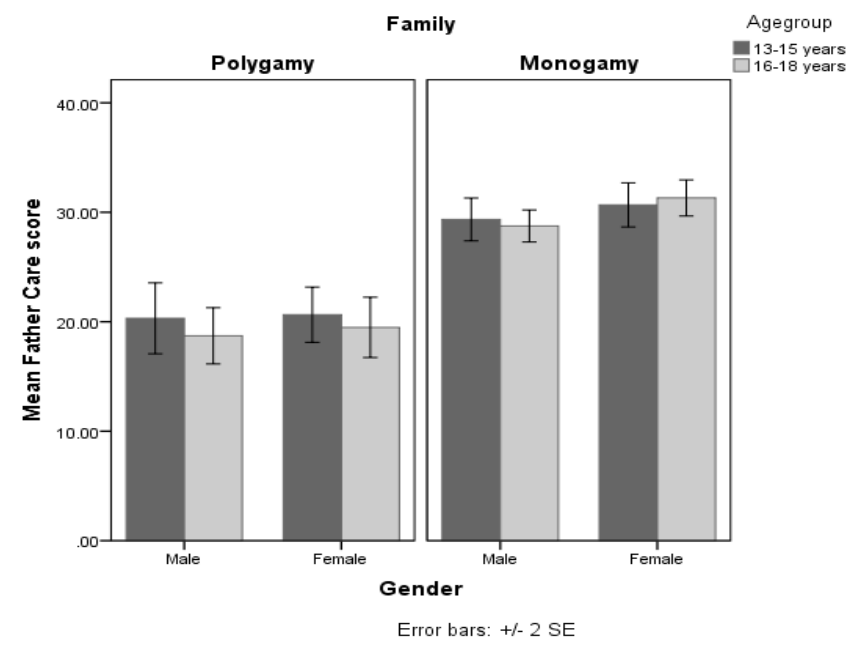

Figure (7)

Mean scores on the Mother Care subscale of the PBI for adolescents from polygamous and monogamous families comparing age group and gender:

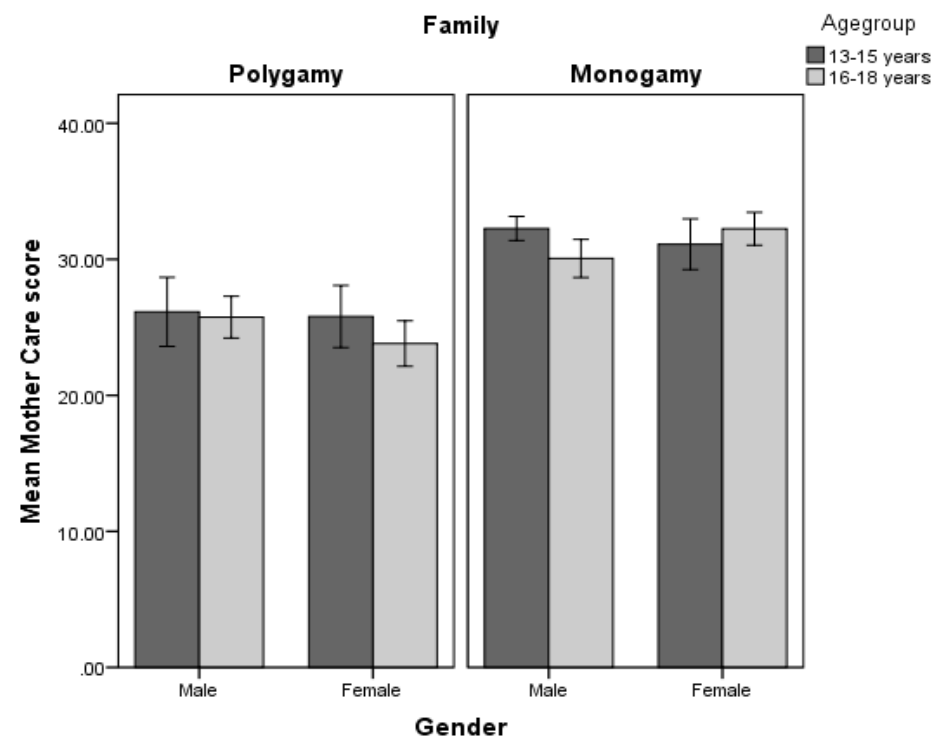

Error bars: +/- $2 \mathrm{SE}$

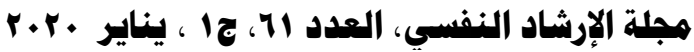




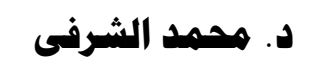

\section{Do adolescent perceptions of parental care predict adolescent well-being and behaviour?}

Multiple regression was used to investigate the relationship between the predictor variables of family type, father care and mother care and the criterion variables of self-esteem, satisfaction with life, depression, bullying and victimization. Using the enter method, significant models emerged for all five criterion variables.

For self-esteem, F $(3,262)=65.087, \mathrm{p}<0.001$, adjusted $\mathrm{R}$ square $=.420$, significant predictors were family (beta $=.362, \mathrm{p}<$ $0.001)$, father care $($ beta $=.258, \mathrm{p}<0.001)$ and mother care $($ beta $=$ $.142, \mathrm{p}=0.02$ ).

For satisfaction with life, $\mathrm{F}(3,262)=59.964, \mathrm{p}<0.001$, adjusted $\mathrm{R}$ square $=.400$, significant predictors were family (beta $=$ $.252, \mathrm{p}<0.001)$, father care (beta $=.314, \mathrm{p}<0.001)$ and mother care (beta $=.182, \mathrm{p}=0.004)$.

For depression, $\mathrm{F}(3,262)=78.160, \mathrm{p}<0.001$, adjusted $\mathrm{R}$ square $=.466$, significant predictors were family (beta $=.417, \mathrm{p}<$ 0.001 ), father care (beta $=.204, p=0.001)$ and mother care (beta $=$ $.181, \mathrm{p}=0.002)$.

For bullying, $\mathrm{F}(3,262)=41.612, \mathrm{p}<0.001$, adjusted R square $=.315$, the only significant predictor was family (beta $=.454, \mathrm{p}<$ $0.001)$. For bully victimization, $F(3,262)=42.446, p<0.001$, adjusted $\mathrm{R}$ square $=.319$, significant predictors were family (beta $=$ $.390, \mathrm{p}<0.001)$ and mother care (beta $=.249, \mathrm{p}<0.001$ ).

In summary, family structure was a significant predictor for self-esteem, satisfaction with life, depression, bullying and victimization. Father care was a significant predictor for self-esteem, satisfaction with life and depression. Mother care was a significant predictor for self-esteem, satisfaction with life, depression and victimization.

\section{Discussion}

Adolescents from polygynous families had poorer self-esteem, poorer satisfaction with life and higher scores on the depression scale than adolescents from monogamous families. Higher rates of bullying behaviour and higher rates of being a victim of bullying were found for adolescents from polygamous families than those from monogamous families. Also, adolescents' perceptions of parental care

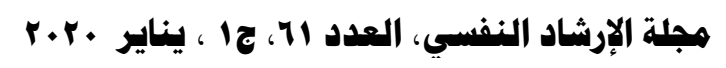


were affected by the type of family structure. Significantly lower scores on the Father Care and Mother Care scales of the PBI were found for adolescents from polygynous families.

The results for self-esteem and satisfaction with life support previous findings of lower self-esteem, negative self-beliefs and negative attitudes towards polygamy among adolescents from polygamous families in Saudi Arabia (Al-Sharfi, 2015), Pakistan (Riaz, 1996) and Bedouin Arabs in the Negev (Al-Krenawi et al., 2002 ; 2006). Scores on the depression scale were found to be higher for adolescents from polygamous families compared to those from monogamous families. Similar results were obtained by Al-Sharfi (2105) in Saudi Arabia, Al-Krenawi et al (2002) and Al-Krenawi and Slonim-Nevo (2008) among Bedouin Arab adolescents. However, some previous studies have reported no differences between adolescents from polygynous and monogamous families in selfesteem and depression (Al-Krenawi \& Slonim-Nevo, 2008; Elbedour et al, 2007; Hamdan et al 2009). Although, this may indicate that cultural differences are important, some inconsistencies have been found in the same cultural context (for example among Bedouin Arabs), suggesting that other variables are important. Other potential variables include the relationships within the family.

Polygamous family structures include different relationships with family members when compared with monogamous marriages (Elbedour, Onwuegbuzie, Caridine, \& Abu-Saad, 2002; Farahat, 2002) and the results from the current study showed that they were perceived as less caring. Adolescents who live in polygamous families have been found to experience many difficulties as a result of their disrupted relationship with their parents (EL-Bedour et al., 2002). Polygynous fathers spend a lot of time away from the family and polygamous families have been found to complain about father absence which has negative effects on adolescents (EL-Bedour et al, 2002). Also the tense relationship between the father and his wives often found in polygamous families may cause the father and mother to show less care toward their adolescents. Mothers in polygamous families face more difficulties than mothers in monogamous families, thus those mothers may have troubled bonding with adolescents as a result of the frustration from dissatisfaction with their marital life

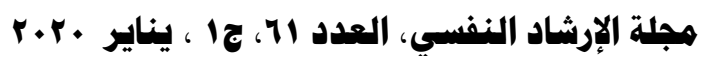


(AL-Krenawi \& Slonim-Nevo, 2006; AL-Shamsi \& Fulcher, 2005). Also, to explain the difficult relationship between fathers and their children in polygamous families, polygamous fathers have been shown to be more controlling of their adolescents than monogamous fathers (AL-Krenawi, Graham \& Al-Krenawi, 1997). In contrast, adolescents from monogamous families reported higher father and mother care giving an indication of the greater stability available in Saudi Arabian monogamous families. In the current study, adolescents' perception of the care given by fathers was a significant predictor for self-esteem, satisfaction with life and depression. The perceptions of the care given by mothers was a significant predictor for self-esteem, satisfaction with life, depression and victimization. Therefore adolescents' perceptions of the quality of the relationship with their parents is important in explaining the relatively poor selfesteem, poor satisfaction with life and higher depression scores for adolescents from polygynous compared to monogamous families.

The higher rates of bullying and victimisation among adolescents from polygamous compared to monogamous families supports previous research by Al-Sharfi (2015) and Al-Krenawi et al (2002). These results could be explained as a negative reaction to a troubled or disrupted family life (Ahmed \& Braithwaite, 2004; Olweus, 1994). Adolescents from polygamous families may commit aggression on their friends at school as an expression of dissatisfaction with family life. However, in the current study, the results for bullying were not predicted by adolescents' perceptions of parental care. Also, the results for bully victimisation were predicted by perceptions of mother care but not father care.

No gender differences were found for any of the variables and there were no interactions between family structure and gender. This supports previous research by Al-Krenawi et al (2002). Although experiences of polygyny are different for men and women, the experiences of male and female offspring of polygynous marriages do not appear to be differentially affected. Also, no differences were found between younger and older adolescents for parental care, selfesteem, satisfaction with life, bullying and victimization. A slight age difference was found for depression, with older adolescents scoring higher than younger adolescents. However, the age group differences

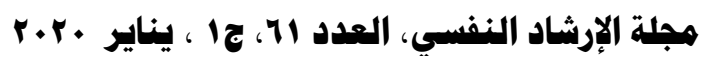


Parental bonding among polygamous families and its effects on adolescent psychological well-being

were not very strong and disappeared when compared for polygamous and monogamous families separately and for boys and girls separately. Also, Saudi society is from Middle East communities that follow strict education systems to prepare boys and girls for adult life and parents continue to be important throughout adolescence and adulthood (Al-Sharfi, 2009).

This study adds to the limited research on the psychological effects of the polygamous family structure on adolescents in general and Saudi adolescents in particular. The results are similar to those from other cultural contexts, especially studies done in other Arab cultural contexts (Al-Krenawi, 2014). Elbedour et al (2002) stated that research on the effects of polygamy on adolescents tends to rely on family structure as a single variable without recognising that family structure involves other potential variables such as family relationships. One of the strengths of this research is that it investigated parent-adolescent relationships and the role of these relationships in predicting adolescent well-being and behaviour. Other strengths of this research are that culturally appropriate and standardised tests were used with good internal consistency. The bullying and victimization questionnaire was designed for use by Arab students and all other tests used had previously been validated for use with Arabic or Middle Eastern samples. For tests designed in the English language, back-translation was used. Limitations of this study include the focus on only one type of potential mediating variable, that is, parent-adolescent relationships. Further research should consider other mediating variables, such as family income, family size, sibling relationships, extended family relationships and the relationships between the adults in the family. This would help to further explain the negative outcomes for adolescents in polygamous families. As this is one of the first studies to investigate the effects of polygamous relationships on Saudi adolescents, the results of this research will be valuable for the Saudi public and school counsellors. Also, this research advances our understanding of polygamous family relationships and the important role of fathers as well as mothers in adolescent well-being and problem behaviour.

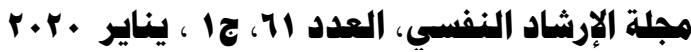



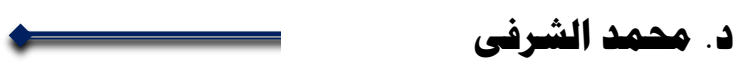

\section{References}

Abu Khazal, M. (2009). Bullying and association with loneliness, social support. Jordan Journal of Educational Sciences, 5 (2), 89113.

Ahmed, E., \& Braithwaite, V. (2004). Bullying and victimization: Cause for concern for both families and schools. Social Psychology of Education, 7(1), 35-54.

Al-Khateeb, S., A. (1981). Bedouin settlement in King of Saudi Arabia: social study for ALguetguet suburb. Social sciences collage, King Saud University.

Al-Krenawi, A. (2014). Psychological impact of polygamy in the Middle East. Springer Publish.

Al-Krenawi, A., Graham, J., Al-Krenwai, S. (1997). Social work practice with polygamous Families. Child and

Adolescent Social Work Journal, 6, 445-458.

Al-Krenawi, A., Graham, J., Slonim-Nevo, V. (2002). Mental health aspects of Arab-Israeli adolescents from polygamous versus monogamous families. Journal of Social Psychology, 142(4) 446460.

Al-Krenawi, A., \& Lightman, E. S. (2000). Learning achievement, social adjustment, and family conflict among Bedouin-Arab children from Polygamous and monogamous families. The Journal of Social Psychology, 3,345-355.

Al-Krenawi, A., Slonim-Nevo, V. (2008). Psychosocial and familial functioning of children from polygamous and monogamous families. Journal of Social Psychology, 148(2), 745-764.

Al-Krenawi, A., Slonim-Nevo, V., \& Graham, J. R. (2006). Polygyny and its impact on the psychological well- being of husbands. Journal of Comparative Family Studies, 3(45), 173189.

Al-Muhareb, N. (2003). Parenting Absence and Aggression, Depression Symptoms. Menoufia University Faculty of Arts Journal, 52, 311-350.

AL-Seef, M. (2008). Family study. [Online] Available: http:// news.bbc.co.uk/hi/ arabic/new S/newside_1305

000/1305844.stm. (Accessed: 10/12/2013).

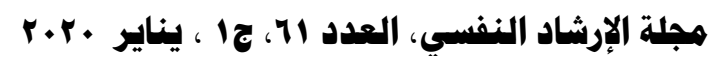


Al-Shamsi, M., \& Fulcher, L. (2005). The impact of polygamy on United Arab Emirates' first wives and their children. International Journal of Child\& Family Welfare, 1, 46-55.

AL-Sharfi, M. (2009). Impact of father absence on gender identity disorder and social competence. Masters thesis. College of Education. King Saud University. Riyadh.

AL-Sharfi, M. (2015). Psychological well-being and bullying/victimization among adolescents from polygamous and monogamous families in Saudi Arabia. Proceedings of the European Conference on Psychology and the Behavioural Sciences 2015, Brighton. United Kingdom.

Al-Sharfi, M., Pfeffer, K., \& Miller, K. A. (2016). The effects of polygamy on children and adolescents: a systematic review. Journal of Family Studies, 22(3), 272-286.

Berk, L. E. (2010). Exploring lifespan development. Boston: Pearson.

Bowlby, J. (1988). A secure base: parent-child attachment and healthy human development. New York: Basic books.

Cherian, V.I. (1994). Corporal punishment and academic achievement of Xhosa children from polygamous and monogamous families. Journal of Social Psychology, 134(3), 387-389.

Diener, E., Emmons, R. A., Larsen, R. J., \& Griffin, S. (1985). The Satisfaction with Life Scale. Journal of Personality Assessment, 49, 71-75.

Elbedour, S., Onwuegbuzie, A. J., Alatamin, M. (2003). Behavioral Problems and scholastic adjustment among Bedouin-Arab families, children from polygamous and monogamous marital structures: Some developmental considerations. Genetic, Social, and General Psychology Monographs, 129(3), 213-237.

Elbedour, S., Onwuegbuzie, A. J., Caridine, C., \& Abu-Saad, H. (2002). The effect of polygamous marital structure on behavioral, emotional, and academic adjustment in children: A comprehensive review of literature. Child and Family Psychology Review, 5(4), 555-271.

Falci, C. D. (1997). The Effects of Family Structure and Family Process on the Psychological Well-Being of Children: From the Children's Point of View (Doctoral dissertation, Virginia Polytechnic Institute and State University).

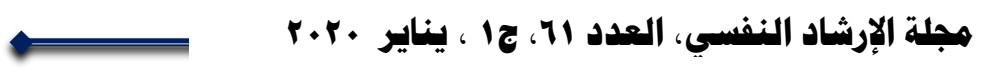


Farahat, Karam. (2002). Polygamy in the religions. Dar- ALafagh. Cairo. Hamdan, S., Auerbach, J., \& Apter, A. (2009). Polygamy and mental health of adolescents. European Child \& Adolescent Psychiatry, 12, 755-760.

Lovibond, P. F., \& Lovibond, S. H. (1995). The structure of negative emotional states: Comparison of the Depression Anxiety Stress Scales (DASS) with the Beck Depression and Anxiety Inventories. Behaviour research and therapy, 33(3), 335-343.

Olweus, D. (1994). Bullying at school: basic facts and effects of a school based intervention program. Journal of child psychology and psychiatry, 35(7), 1171-1190.

Parker, G., Tupling, H., and Brown, L.B. (1997). A Parental Bonding Instrument. British Journal of Medical Psychology, 52, 1-10.

Riaz, M. (1996). Self-esteem of adolescents: A compression of monogamous and polygamous families. Pakistani Journal of Psychological Research, 1, 21-30.

Rigby, K., Slee, P. T., \& Martin, G. (2007). Implications of inadequate parental bonding and peer victimization for adolescent mental health. Journal of Adolescence, 30(5), 801-812.

Rosen, K.S. (2016). Social and emotional development: Attachment relationships and the emerging self. Palgrave.

Rosenberg, M., (1965). Society and the adolescents' self-image. Preincton, NJ: Princetion University press.

Shepard, L. D. (2013). The impact of polygamy on women's mental health: A systematic review. Epidemiology and Psychiatric Sciences, 22, 47- 62.

Sun, Y. (2001). Family environment and adolescents' well-being before and parents' disruption: longitudinal analysis. Journal of Marriage and Family, 63, 697-713.

Swanson, R. B., Masssey, R. H., \& Payne, I. R. (1972). Ordinal position, family size, and personal adjustment. Journal of Psychology, 81, $51-58$.

Valsiner, J. (1989). Organization of children's social development in polygamic families. In J. Valsiner $(E d$.), Child development in cultural context (pp. 67-86). Toronto, Canada: Hogrefe and Huber.

Yamani, M. (2008). Polygamy and Law Contemporary Saudi Arabia. Islamic Law and Society, 17, 279-290.

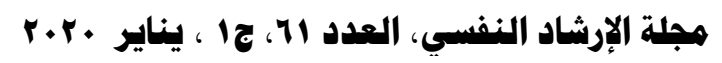

